\title{
MICROPROPOGATION AND PHYTOCHEMICAL PROFILE ANALYSIS OF TISSUE CULTURE GROWN PLANTAGO OVATA FORSK
}

\author{
MAMTA SHARMA*, AMITA KUMARI, ESHITA MAHANT \\ School of Biological and Environmental Sciences, Shoolini University, Solan, Himachal Pradesh, India. \\ Email: mamtasharma@shooliniuniversity.com
}

Received: 09 December 2016, Revised and Accepted: 24 January 2017

\begin{abstract}
Objective: Plantago ovata is an important medicinal plant of the Himalayan region which is greatly used in herbal drugs manufacturing. The plant is multipurpose constrained in Himalayan regions. Plantago has many medicinal properties such as antioxidant, anti-inflammatory, hematopoiesis effects, and used for the treatment of cancer. Plantago contains copious amount of mucilage that is able to treat diarrhea, constipation, and act as an effective weight loss aid. The plant being medicinal possesses complex phytochemicals. The investigation of various Plantago organs (leaves, stem, etc.) revealed their high potential to produce a wide array of bioactive secondary metabolites. In the present study, a new method of micropropagation through tissue culture was developed for Plantago so as to meet the future demand of plant. Further, a morphological and physiochemical comparison of tissue culture grown plant was done with in vivo grown plants.
\end{abstract}

Methods: P. ovata was grown in vitro through tissue culture technique using Murashige and Skoog media and in vivo in the nursery area of Shoolini University. The tissue culture of $P$. ovata Forsk was managed to restrict the ecological factors. Experimentally, parameters including germination growth and phytochemical constituents of plant in vivo and in vitro conditions were observed.

Results: The result revealed an easy method for the micropropagation of Plantago. However, changes in the concentration of phytochemical constituent's in tissue culture grown Plantago were reported in comparison to in vivo grown plants. Phytochemicals constituents (carbohydrate, chlorophyll, saponin, and tannin) were reduced in tissue culture grown plant whereas some phytochemicals (phenol, alkaloid, Flavonoid, protein, and phytosterol) increased in tissue culture grown plant than in vivo plant. A reduction in morphological trait was found in tissue cultured plant.

Conclusion: The developed tissue culture method for the micropropagation of $P$. ovata can be proved as a landmark to meet the industrial need in the near future.

Keywords: Plantago, Tissue culture technique, Germination, Phytochemicals.

(C) 2017 The Authors. Published by Innovare Academic Sciences Pvt Ltd. This is an open access article under the CC BY license (http://creativecommons. org/licenses/by/4. 0/) DOI: http://dx.doi.org/10.22159/ajpcr.2017.v10i4.16532

\section{INTRODUCTION}

India has a rich heritage of a great variety of plant species and is one of the world's top 12 mega diversity countries rich in biodiversity resources. The Himalayan region is basically referred as the cradle of flowering plants, and the most interesting part is that the region boosts of having more than 400 species of medicinal plants. Medicinal plants are used in the Ayurvedic, Unani, and other traditional system of medicine- and plant-based pharmaceutical industries. Medicinal plants contain some organic compounds which provide definite physiological action on the human body, and these bioactive substances include tannins, alkaloids, carbohydrates, terpenoids, steroids, and flavonoids. Studying medicinal plants help to understand plant toxicity and protect human and animals from natural poisons. Cultivation and preservation of medicinal plants protect biological diversity by metabolic engineering of plants. Plantago, family Plantaginaceae, is a large genus comprising 200 species including herbs or subshrubs distributed mostly in the temperate regions and few in tropics. About ten species are recorded in India, of which Plantago ovata is important for its seeds. P. ovata is a stemless or subcaulescent soft, hairy, or woolly annual herb which attains a height of $30-45 \mathrm{~cm}$.

Tissue culture technique is a science of growing plant cells, tissues, or organs isolated from the mother plant. It includes techniques and methods used to research into many botanical disciplines and have several practical objectives. It is an experimental technique through which mass of cell is produced from the explants tissue. The callus produced can be utilized directly to regenerate plantlets to extract and manipulate some primary and secondary metabolites. The plant and tissue cultures have been enabled to increase the knowledge in many areas including differentiation, cell division, cell nutrition, and cell preservation, but now, cells are cultivated in vitro in bulk or as clone from single cell to grow whole plants from isolated meristem, then induce callus and develop complete plantlets by organogenesis or by meristem, then induce callus and develop complete plantlets by organogenesis or by embryogenesis [1,2]. A single explant can be multiplied into several thousand plants in relatively short time and space under controlled conditions, irrespective of the season and weather on a year-round basis $[3,4]$. Endangered, threatened, and rare species have successfully been grown and conserved by micropropagation because of high coefficient of multiplication and small demands on a number of initial plants and space [5]. Commercial production of plants through micropropagation techniques has several advantages over the traditional methods of propagation through seed, cutting, grafting and air-layering, etc. Till date, P. ovata has not been grown through tissue culture technique, and the present work gave a new method for the micropropagation of Plantago to meet the industrial needs.

\section{METHODS}

The purpose of the present study was to grow $P$. ovata through tissue culture and compare its morphological and phytochemical characteristics with naturally grown plant. The seed was collected in October 2015 from Dr. YS Parmar University of Horticulture and Forestry, Nauni, Solan (Himachal Pradesh). Experiments were 


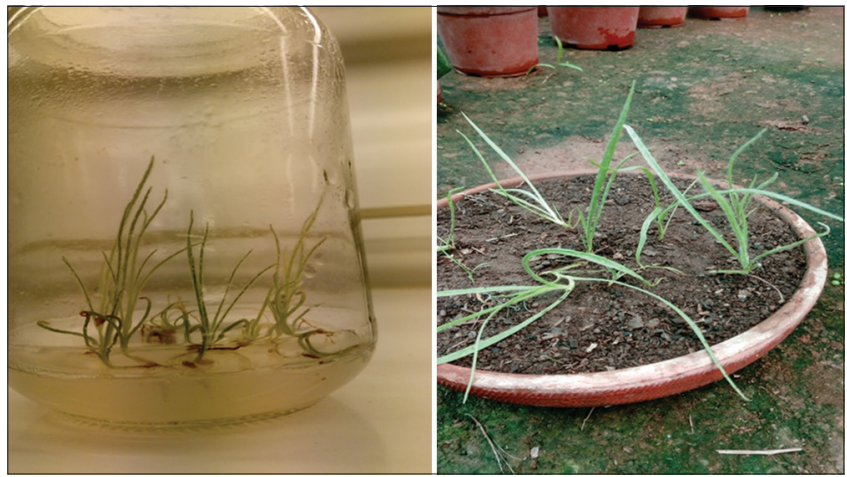

Fig. 1: In vitro (tissue culture technique) grown Plantago ovata

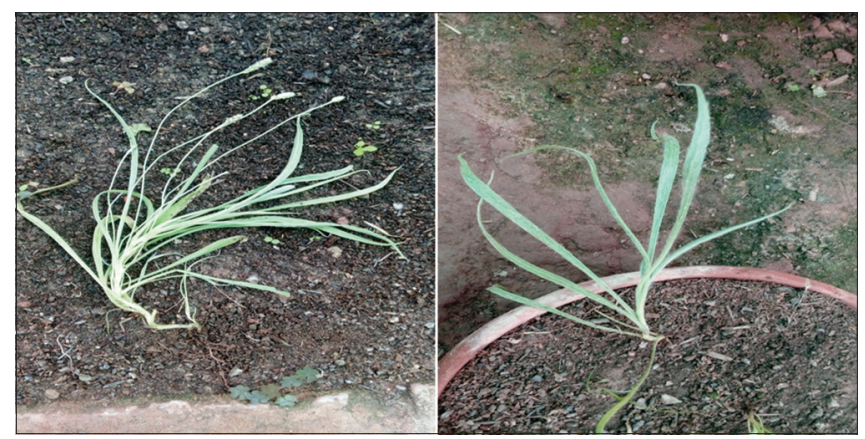

Fig. 2: Plantago ovata grown in vivo and in vitro conditions

conducted in the tissue culture laboratory and nursery area of Shoolini University, Solan (Fig. 2).

\section{Seed germination in vivo}

The seeds of $P$. ovata were selected in uniformity and surface sterilized with $1 \%$ of sodium hypochlorite for 5 minutes, followed by washing with tap water. The seeds were transferred to Petri plates $(100 \mathrm{~mm} \times 15 \mathrm{~mm})$ lined with two layers of filter paper moistened with distilled water. The seeds were then allowed to germinate in an incubator at $25 \pm 5^{\circ} \mathrm{C}$ under continuous illumination provided by florescent white light. When the first leaf appeared, the seedlings were transferred to the pots. To eliminate pathological effect of soil, physiochemical characteristics of soil were analyzed including $\mathrm{pH}$, electrical conductivity, moisture content, and soil texture.

\section{Seed germination in vitro}

The plants of $P$. ovata were selected in uniformity (on the basis of color and size), and further sterilization technique was applied. The seeds were taken in the tea strainer/nylon net pouch/muslin cloth and wash in running tap water. The infected seeds were first washed in a beaker with few drops of liquid detergent. After washing, the seeds were treated with $70 \%$ of alcohol for 30 seconds to 2 minutes in a beaker. The seeds were treated with $20-40 \%$ of solution of sodium hypochlorite solution containing 2-3 drops of tween 20 for 10-20 minutes with stirring. In a sterile laminar air flow hood, decant the chemical sterilant and wash the seeds thoroughly 5 times with sterile distilled water. Inoculation was done in the tissue culture laboratory on Murashige and Skoog media, and then the seeds were allowed to grow in tissue culture laboratory, and the germination was recorded regularly (Fig. 1).

\section{Phytochemical extraction}

Each powdered plant material was subjected to successive solvent extraction with methanol, ethyl acetate, and chloroform. Proportion of material to solvent was taken as 1:10. Material subjected to Soxhlet extraction with different solvents for $72 \mathrm{hrs}$ and filtered with Whatman filter paper No. 1. Extract used to analysis to explore the phytoconstituents such as tannins, alkaloids, saponins, terpenoids, phytosterol, and flavanoids using the standard protocols.

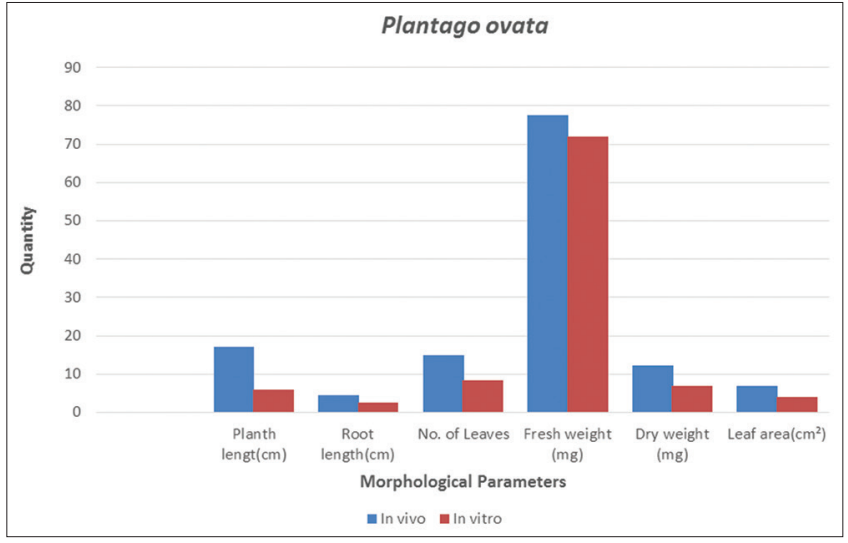

Fig. 3: Variation in the morphological parameters of tissue cultured grown Plantago ovata and in vivo grown plant

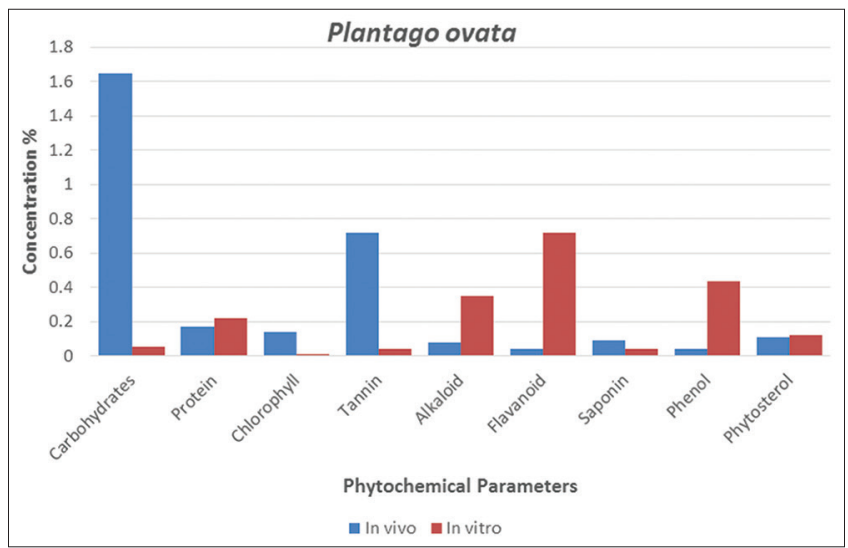

Fig. 4: Variation in the morphological parameters of tissue cultured grown Plantago ovata Forsk and in vivo grown plant

\section{Phytochemical analysis of $P$ ovata}

Qualitative tests for the detection of carbohydrates were done with Molish and Benedicts test, detection of protein and amino acids by ninhydrin test and xanthoprotein test, detection of tannins by ferric chloride test, detection of flavonoids by lead acetate test and ferric chloride test, and detection of alkaloids by Mayer's test and Wagner's test were performed (Figs. 3 and 4). Quantitative estimation of total carbohydrate [6], protein [7], alkaloids [8], flavanoids [9], tannins [10], phenols [11], saponins [12], phytosterols [13], and estimation of chlorophyll [14] was done.

\section{Statistical analysis}

The data were analyzed statistically using GraphPad Prism ${ }^{\circledR} 5.2$ and SPSS. Mean values were calculated from measurements of three replicates, and the standard error of means was determined. Unpaired t-test was applied to determine the significance of results between different studied plants.

\section{RESULTS}

In the present study, plant $P$. ovata Forsk of family Plantaginaceae was selected for morphological analysis including height of plant, root length, number of leaves, fresh weight, dry weight, and leaf area (LA) and phytochemical analysis (carbohydrate, protein, saponin, flavonoids, alkaloids, phytosterol, tannins, chlorophyll, and phenol).

Plant height increased with the growing stages in vivo and in vitro condition. Tissue culture grown seedlings showed $65 \%$ reduction in plant height in vitro condition in comparison to $35 \%$ of the height of plant in vivo condition (Table 1). Root length showed variation in root growth in different conditions. The result revealed that the root length 
Table 1: Variation in the height of plant, root length, number of leaves, fresh weight of a leaf, dry weight of a leaf, and the LA of the control plant and tissue culture grown plant

\begin{tabular}{llll}
\hline S.No. & Parameter & Control & In vitro \\
\hline 1. & Height of plant $(\mathrm{cm})$ & $17 \pm 0.816$ & $06 \pm 1.632$ \\
2. & Root length $(\mathrm{cm})$ & $4.5 \pm 0.408$ & $2.5 \pm 1.779$ \\
3. & Number of leaves & $15 \pm 0.816$ & $8.3 \pm 0.471$ \\
4. & Fresh weight of a leaf $(\mathrm{mg})$ & $77.6 \pm 3.858$ & $72 \pm 5.099$ \\
5. & Dry weight of a leaf $(\mathrm{mg})$ & $12.3 \pm 3.299$ & $07 \pm 2.499$ \\
6. & LA $\left(\mathrm{cm}^{2}\right)$ & $07 \pm 1.632$ & $04 \pm 0.816$ \\
\hline
\end{tabular}

Values are of mean \pm standard error. LA: Leaf area

Table 2: Variation in qualitative analysis of $P$. ovata grown in vivo plant and in vitro

\begin{tabular}{lll}
\hline Secondary metabolites & In vivo & In vitro \\
\hline Carbohydrates & + & + \\
Phenol & + & + \\
Flavonoids & + & + \\
Alkaloid & + & + \\
Phytosterol & + & + \\
Chlorophyll & + & + \\
Saponin & + & + \\
Protein & + & + \\
Tannins & + & + \\
\hline P. ovate: Plantago ovata & &
\end{tabular}

Table 3: Variation in quantitative analysis of $P$. ovata grown in vivo and in vitro

\begin{tabular}{lll}
\hline Secondary metabolites & In vivo & In vitro \\
\hline Carbohydrates & $1.645 \pm 0.001$ & $0.057 \pm 0.020$ \\
Phenol & $0.041 \pm 0.002$ & $0.439 \pm 0.013$ \\
Tannin & $0.717 \pm 0.021$ & $0.046 \pm 0.012$ \\
Chlorophyll & $0.144 \pm 0.004$ & $0.014 \pm 0.001$ \\
Alkaloid & $0.078 \pm 0.011$ & $0.350 \pm 0.007$ \\
Flavanoid & $0.045 \pm 0.003$ & $0.717 \pm 0.029$ \\
Saponin & $0.093 \pm 0.012$ & $0.045 \pm 0.046$ \\
Protein & $0.174 \pm 0.007$ & $0.222 \pm 0.125$ \\
Phytosterol & $0.108 \pm 0.008$ & $0.125 \pm 0.002$ \\
\hline
\end{tabular}

P. ovate: Plantago ovata

in case of in vivo grown plant is larger as compare to tissue culture grown plant. The root length in tissue culture grown plant shows reduction by $45 \%$ as compared to in vivo grown plant. Root length of in vitro plant is $55 \%$ as compared to in vivo grown plant. Number of leaves of 60 days old plant grown in vivo and in vitro conditions were measured. Number of leaves showed variation in different conditions. The result revealed that number of leaves in case of in vivo grown plant is more as compare to tissue culture grown plant. Number of leaves in vitro plant is $55 \%$ as compared to in vivo grown plant. A reduction in the fresh weight of the plant was found in vitro plant as compared to in vivo grown plant. Fresh weight was found slightly higher in case of in vivo grown plant. The degree of decrease in fresh weight of tissue culture plant was $7 \%$ compared to in vivo plant. A reduction in the dry weight of the plant was found in vitro plant as compared to in vivo grown plant. The degree of decrease in dry weight of tissue culture plant was $43 \%$ compared to in vivo plant. LA of the 60 days old plant grown in vivo and in vitro conditions was measured. It showed inconsistent variation. As expected, progressive increase in LA was noted in the in vivo plant but reduced in plant growth in vivo conditions where reduction of $43 \%$ was found in the plant grown in vitro conditions.

\section{Phytochemical parameters}

Qualitative analysis of phytochemicals showed no variation in the presence or absence of phytochemicals (carbohydrates, phenols, flavanoids, alkaloids, phytosterol, chlorophyll, saponins, protein, and tannin) in the control plant and tissue culture grown plant. All the secondary metabolites estimated are present in both the cases.

Total carbohydrate content was measured in 60 days old plant grown in vivo and in vitro conditions quantitatively (Table 2). Carbohydrate content was found to be more in case of in vivo plant compared to in vitro. Phenol content was found to be more in case of tissue culture grown plant as compared to normally grown plant.

Tannin content was found to be more in case of in vivo plant compared to in vitro. Total chlorophyll content was measured in 60 days old plant grown in vivo and in vitro conditions (Table 3). Chlorophyll content was found to be decreased in case of in vitro as compared to in vivo plant. Similarly, protein content was found to be affected by in vitro condition as it increased by $30 \%$ in comparison to in vivo plant. Alkaloid content was found to be affected by in vitro condition where it increased by $35 \%$ as compared to in vivo plant. Flavonoid content also showed variation and was found to be increased by $90 \%$ as compared to in vivo plant. Phytosterol content was found to be affected where $15 \%$ increase was reported. Saponin content was found to be more in case of in vivo plant (12\%) compared to in vitro (tissue culture grown plant).

\section{DISCUSSION}

The aim of the present study was to understand the comparative account of morphology and phytochemicals of a plant (P. ovata) grown in two different conditions. The plant was grown in vivo condition in the herbal garden of Shoolini University and in vitro condition through tissue culture technique. Analysis of morphological parameter revealed that plant height, root length, number of leaves, fresh weight of leaf, dry weight of leaf, and LA were higher in control plants in comparison to tissue culture grown plants. Furthermore, the highest values of morphological parameters including stem length, root length, fresh weight, dry weight, and number of leaves belonged to control plants, whereas the highest value of phytochemical constituents was reported in plants belonged to tissue culture grown plants. P. ovata is an annual herb that grows to a height of 30-46 cm (12-18 in). Study revealed reduction in root length in tissue culture grown plant in comparison to control. The root length of the control plant and tissue culture grown plant varies as the root length of control plant is higher than that of tissue culture grown plant. The root formation of shoots was best on half-strength medium supplemented with 3-indolebutyric acid. Number of leaves is more in case of control plant and less in case of tissue culture grown plant. Mean LA of single leaf was the lowest in Plantago arenaria $\left(2.81 \mathrm{~cm}^{2}\right)$ which was at par with that of Plantago psyllium and Plantago lanceolata had the highest [15]. Fresh weight is of leaf declined in case of tissue culture grown plant, whereas it is increasing in control plant. Dry weight is of leaf decreasing in case of tissue culture grown plant, whereas it is increasing in control plant. LA of control plant is more than that of tissue culture grown plants. It was found that GA3 has a significant effect on the root elongation as it promotes cell division and cell elongation [16]. Regarding this experiment, the root length was not much increased by the application of growth hormones. The reported results are in agreement with $[17,18]$. It was demonstrated that utility of mineral oil in reducing shoot-bud regeneration from the callus of Plantago major (180 days instead of 45-60 days for control) with a regeneration ratio of $82 \%$ [19]. The mineral oil overlay technique could appreciably reduce the cost of maintenance of tissue cultures. Moreover, the mineral oil used over alginate beads was reported to protect encapsulated explants from desiccation and microbial attack [20].

Plantago is an important medicinal plant which has different compounds such as phenolic compounds (caffeic acid derivatives), flavonoids, alkaloids, terpenoids, and vitamin C5. In a study conducted in Jabalpur [21], germplasm of P. ovata was compared in terms of their protein percentage, inflation rate, fat percentage, crude fiber (in percent), and seed shells [22]. Plantago plants have high levels of phenol, and the powerful antioxidant quality of the plant may be due to its phenolic compounds. Phenol content was reported to be increased in Plantago grown through tissue culture technique. 
It was found that flavonoid content of Plantago major organdependent, i.e., calli (ranging from $0 \%$ DW to $20 \%$ DW), plantlets (30\% DW), shoot cultures (10\% DW), root cultures $(40 \% \mathrm{DW})$, and ex vitro plants $(60 \%$ DW) [23]. Higher levels of flavonoids were recorded in in vitro plants and undifferentiated tissues contained less than organized tissues. Such differences in the levels of secondary metabolites between whole plants and cell or tissue cultures have often been described $[24,25]$. In addition, $P$. major calli with the highest growth rates contained the lowest levels of flavonoids. This is why for industrial production of secondary metabolites a great number of protocols involve two steps: The first one involves tissue or cell culture in a growth medium followed by a subculture step using a production medium $[26,27]$.

Based on the researches, the phenolic compounds of Plantago plant is used against UV radiation. The anti-mutation activities of phenolic compounds are associated with its antioxidant activity because phenolic compounds in the presence of free radicals lead to the inhibition of DNA damage [28]. Alkaloid and flavanoid contents in tissue culture grown plant are high as compared to control plant. An alteration in carbohydrate content has been found in the study [29]. The carbohydrate content is found more in case of control plant and less in case of tissue culture grown plant. This forage plant contains 2-6.5\% mucilage which is composed of at least four polysaccharide, $6.5 \%$ tannin, anvrtyn, emulsions, and a glycoside called aucubin, diastase, hetrozeid, coloring materials, pectin, plantagin, more than $1 \%$ salicylic acid, carboxylic phenolics acids, flavonoids, minerals, including zinc, potassium, silicic acid, and saponin. Saponin and tannin were found less in tissue culture grown plant than the control plant [29]. Chlorophyll was found more in case of control plant and is found reduced in tissue culture grown plant.

There was a remarkable variation in the morphological parameter and phytochemical in the P. ovata studied grown in two different conditions. The higher biomass was noticed in P. ovata. There was a positive correlation between total biomass among the plant grown in two different conditions, and much variation is seen in the phytochemical (carbohydrate, phenol, tannin, chlorophyll, protein, alkaloid, flavonoid, and saponin) present in the plant. In conclusion, leaf characteristics show variation in its number, area, fresh, and dry weight. These characters may be considered in the breeding programs for the yield improvement.

\section{CONCLUSION}

The aim of this study was to determine the phytochemical constituents in P. ovata in vivo and in vitro conditions. A reduction in morphological character was found in vitro (Tissue Culture Technique) grown plant as compared to in vivo plant. In the study of phytochemical constituents of the plant phytochemical such as carbohydrate, tannin and saponin are found reduced in vitro grown plant and phytochemical constituents phenol, protein, alkaloid, flavanoid, and chlorophyll were increased in vitro grown plant. Phytochemical investigations of Plantago species reveal their high potential to produce a wide array of bioactive secondary metabolites, i.e., polyphenols, polysaccharides, and sterols (Li et al., 1995; Samuelsen et al., 1995; Afifi et al., 2001; Grubesic and Vladimir-Knjezevic, 2004) that have utility as supplemented feed (Tamura et al., 2002) and as drugs to treat human diseases (Chiang et al., 2003; Hetland, 2003). Regarding the culture conditions of Plantago species, most of the well-known parameters influencing seed germination and seedlings growth belong to both physical and chemical types, i.e., temperature, humidity, light, substrates with or without additional nutritive solutions, and culture media with or without growth regulators (Gjerstad, 1961; Ladeira et al., 1987; George, 1993; Gutterman, 2000; Makowczynska and Andrzejewska-Golec, 2003; 2004; Budzianowska et al., 2004; Li and Li, 2005). In vitro cultures allow effective micropropagation in particular of $P$. ovata which presents a great economical stake for India (Pramanik et al., 1994) and widely used in Egypt for his pharmacological interest (Saker and Kawashity, 1998). It is concluded by overall study that morphological character and concentration of phytochemical constituents varies in the plants grown in vivo and in vitro conditions. Morphological characters are found to be reduced in tissue culture grown plant and much variation is found in phytochemical constituents. The result of the present study can be used as a baseline for further study involving screening and selection of tolerant genotypes and using these traits in breeding programs. Tissue culture technique is a good technique to mass multiply the Plantago to meet the requirement of drug development and recovery in the near future.

\section{ACKNOWLEDGMENT}

Authors are thankful to the Faculty of Shoolini University of Biotechnology and Management Sciences, Solan, for their suggestions and laboratory facilities.

\section{REFERENCES}

1. Abbas JA, El Oqlah AA, Mahaneh AM. Herbal plants in the traditional medicine of Bahrain. Econ Bot 1992;46(2):158-63.

2. Agnihotri K, Ansari SA. Adventitious rhizogenesis in relation to seasonal variation, size of culm branch cuttings and IAA treatment in bamboos. Indian Forester 2000;126(9):971-84.

3. Agnihotri RK, Nandi SK. In vitro shoot cut: A high frequency multiplication and rooting method in the bamboo Dendrocalamus hamiltonii. Biotechnology 2009;8(2):259-63.

4. Anderson JW, Allgood LD, Turner J, Oeltgen PR, Daggy BP. Effects of psyllium on glucose and serum lipid responses in men with Type 2 diabetes and hypercholesterolemia. Am J Clin Nutr 1999;70(4):466-73.

5. Begum S, Hassan SI, Siddiqui BS, Shaheen F, Ghayur MN, Gilani AH. Triterpenoids from the leaves of Psidium guajava. Phytochemistry 2002;61(4):399-403.

6. Bentley R, Trimen H. Medicinal Plants. Vol. 3. Dehra Dun, India: Allied Book Centre; 1981. p. 211-7.

7. Budzianowska A, Skrzypczak L, Budzianowski J. Phenylethanoid glucosides from in vitro propagated plants and callus cultures of Plantago lanceolata. Planta Med 2004;70(9):834-40.

8. Caccioni DR, Tonini G, Guizzardi M. In vitro antifungal activity of some South African medicinal plants. S Afr J Bot 2002;68:72-6.

9. Che J, Li M, Jin Z. Current research and development of plant polyphenols as skin care factors in cosmetics. Heil Yi 2006;19:97-9.

10. Cristoni A, Morazzoni P. Botanicals for innovative cosmenutraceuticals. J Appl Cosmetol 2003;21:9-22.

11. Deters AM, Schröder KR, Smiatek T, Hensel A. Ispaghula (Plantago ovata) seed husk polysaccharides promote proliferation of human epithelial cells (skin keratinocytes and fibroblasts) via enhanced growth factor receptors and energy production. Planta Med 2005;71(1):33-9.

12. Dhar MK, Kaul S, Sareen S, Koul AK. Plantago ovata: Genetic diversity, cultivation, utilization and chemistry. Plant Genet Resour 2005;3(2):252-63.

13. Dijkstra P, Kuiper PJ. Effects of exogenously applied growth regulators on shoot growth of inbred lines of Plantago major differing in relative growth rate: Differential response to gibberellic acid and (2-chloroethyl)trimethyl-ammonium chloride. Plant Physiol 1989;77(4):512-8.

14. Dijkstra P, Reegen H, Kuiper PJ. Relation between relative growth rate, endogenous gibberellins, and the response to applied gibberellic acid for Plantago major. Physiol Plant 1990;79(4):629-34.

15. Fischer MH, Yu N, Gray GR, Ralph J, Anderson L, Marlett JA. The gel-forming polysaccharide of psyllium husk (Plantago ovata Forsk). Carbohydr Res 2004;339(11):2009-17.

16. Fons F, Gargadennec A, Gueiffier A, Roussel JL, Andary C. Effects of cinnamic acid on polyphenol production in Plantago lanceolata. Phytochemistry 1998;49(3):697-702.

17. Han GY, Wang XF, Zhang GY, Ma ZY. Somatic embryogenesis and plant regeneration of recalcitrant cottons (Gossypium hirsutum). Afr J Biotechnol 2009;8(3):432-7.

18. Jamal S, Ahmad Y, Agarwal R, Ahmad M, Osman SM. A novel oxo fatty acid in Plantago ovata seed oil. Phytochemistry 1987;26(11):3067-9.

19. Jasrai YT, Yadava N, Mehta AR. Somatic embryogenesis from leaf induced cell cultures of Plantago ovata Forsk. J Appl Sci Res 1993;7:327-32.

20. Kalyansundram, NK, Patel PB, Dalal KC. Nitrogen need of Plantago ovata Forsk in relation to the available nitrogen in the soil. Int J Agric Sci 1982;52:240-2

21. Kalyansundram NK, Sriram S, Patel BR, Patel DH, Dalal KC, Gupta R. Psyllium: A monopoly of Gujarat. Indian J Hortic 1984;28(4):35-7. 
22. Karimzadeh G, Omidbaigi R. Growth and seed characterization of Isabgol (Plantago ovata Forsk) as influenced by some environmental factors. J Agric Sci Technol 2004;6(3-4):103-8.

23. Khawar KM, Sarihan EO, Sevimay CS, Çöçü S, Parmaksiz I, Uranbey S, et al. Adventitious shoot regeneration and micropropagation of Plantago lanceolata L. Period Biol 2005;107:113-6.

24. Patel RB, Rana NG, Patel MR. Chromatographic screening of proteins of Plantago ovata Forsk. Indian J Pharm Sci 1979;41(4):249-53.

25. Pramanik S, Chakraborty S, Raychaudhuri S. In vitro clonal propagation and characterization of clonal regenerants of Plantago ovata Forsk by isozyme analysis. Cytobios 1995;82:123-30.
26. Kurian S, Josekumar VS. Phytochemical screening, antimicrobial activity and brine shrimp lethality bioassay of different extracts of Alysicarpus vaginalis var. Nummularifolius (DC.) Miq. Int J Pharm Pharm Sci 2017;1:166-71.

27. Sarmah P, Kobing N, Gogoi J, Dutta AM. In vitro anthelmintic and antiamylase properties of Garcinia pedunculata Roxb. ethanolic extract. Int J Pharm Pharm Sci 2017;9(1):189-91.

28. Rahn K. A phylogenetic study of the Plantaginaceae. Bot J Linn Soc 1996;120(2):145-98.

29. Zafar R, Aeri V, Datta A. Application of plant tissue and cell culture for production of secondary metabolites. Fitoterapia 1992;63:33-43. 